\title{
$C C N J$ detected by triple combination array analysis as a tumor-related gene of hepatocellular carcinoma
}

\author{
NAO TAKANO ${ }^{1}$, MITSUHIRO HISHIDA ${ }^{1}$, YOSHIKUNI INOKAWA ${ }^{1}$, MASAMICHI HAYASHI ${ }^{1}$, MITSURO KANDA ${ }^{1}$, \\ YOKO NISHIKAWA ${ }^{1}$, NAOKI IWATA ${ }^{1}$, DAISUKE KOBAYASHI ${ }^{1}$, CHIE TANAKA $^{1}$, SUGURU YAMADA $^{1}$, \\ GORO NAKAYAMA ${ }^{1}$, TSUTOMU FUJII ${ }^{1}$, HIROYUKI SUGIMOTO ${ }^{1}$, MASAHIKO KOIKE ${ }^{1}$, \\ MICHITAKA FUJIWARA ${ }^{1}$, YASUHIRO KODERA ${ }^{1}$ and SHUJI NOMOTO ${ }^{1,2}$ \\ ${ }^{1}$ Gastroenterological Surgery, Nagoya University Graduate School of Medicine, Showa-ku, Nagoya 466-8550; \\ ${ }^{2}$ Department of Surgery, Aichi-Gakuin University School of Dentistry, Chikusa-ku, Nagoya 464-8651, Japan
}

Received November 23, 2014; Accepted January 21, 2015

DOI: $10.3892 /$ ijo.2015.2892

\begin{abstract}
Hepatocellular carcinoma (HCC) has a high likelihood of recurrence and a poor prognosis. To detect cancer-related genes of HCC, we developed a new technique: triple combination array analysis, consisting of a methylation array, a gene expression array and a single nucleotide polymorphism array. A surgical specimen obtained from a 68-year-old female HCC patient was analyzed using triple combination array, which identified cyclin $\mathrm{J}(C C N J)$ as a candidate cancerrelated gene of HCC. Subsequently, samples from $85 \mathrm{HCC}$ patients were evaluated for $C C N J$ promoter hypermethylation and expression status using methylation-specific PCR (MSP) and quantitative reverse transcriptase RT-PCR, respectively. $C C N J$ was found to be hypermethylated (methylation value, 0.906; range, 0-1.0) in cancer tissue, compared with adjacent non-cancerous tissue $(0.112)$ using a methylation array. MSP revealed that $C C N J$ was hypermethylated in $67(78.8 \%)$ of the tumor samples. $C C N J$ expression was significantly decreased in cases with hypermethylation $(\mathrm{P}<0.0001)$. Furthermore, cases with both promoter hypermethylation and decreased expression of $C C N J$ in the tumor tissue had a worse overall survival than the other cases $(\mathrm{P}=0.0383)$. In conclusion, our results indicated that $C C N J$ could be a novel prognostic marker of HCC, and this study indicated that triple combination array analysis was effective in detecting new tumor-related genes and their mechanisms.
\end{abstract}

\section{Introduction}

Hepatocellular carcinoma (HCC) accounts for $80-90 \%$ of primary liver cancers, and is the sixth leading cause of death

Correspondence to: Dr Shuji Nomoto, Department of Surgery, Aichi-Gakuin University School of Dentistry, 2-11 Suemori-dori, Chikusa-ku, Nagoya 464-8651, Japan

E-mail: snomoto@dpc.agu.ac.jp

Key words: cyclin J, hepatocellular carcinoma, methylation, triple combination array, cancer-related gene from cancer worldwide (1). Today, developments in imaging have enabled the detection of $\mathrm{HCC}$ at an early stage and new therapeutic options for HCC have improved survival rates (2-5). However, HCC still has high recurrence rates after surgical resection, with most recurrences being confined to the remnant liver $(6,7)$. Therefore, it is important to identify genetic markers relevant to the oncogenesis of HCC (8).

We reported a novel method named double-combination array that combines a gene expression array and a single nucleotide polymorphism (SNP) array, and have developed this method and reported a number of cancer-related genes in HCC (9-14). Through these studies, we hypothesized that the decrease in expression of these genes could be caused by DNA methylation of the $\mathrm{CpG}$ islands in the promoter region, and would lead to HCC progression. In addition to the double-combination array analysis, we obtained further data from the same specimens using methylation array analysis to make this association with DNA methylation more conclusive. Thus, this triple combination array analysis seems to be an efficient procedure for the detection of cancer-related genes of HCC (15-17).

From our triple combination array analysis, cyclin $\mathrm{J}(C C N J)$ was identified as one of the new candidate cancer-related genes of HCC. Cyclin family members, known as cell cycle regulators, play important roles in cell proliferation and are linked to cell carcinogenesis. The function of most cyclins in human cancer, including HCC, has been reported to be oncogenic. However, some cyclins play suppressive roles in carcinogenesis or cancer progression (18-23). The function of CCNJ in humans is still unclear and there are only a few reports of a relationship between $C C N J$ and cancer, although there have been no previous studies on the role of $C C N J$ in $\operatorname{HCC}(24,25)$. We predicted $C C N J$ might be involved in the cell cycle in human HCC and evaluated the expression and methylation status and investigated clinicopathological features of $\mathrm{CCNJ}$ in $\mathrm{HCC}$ cases.

\section{Materials and methods}

Ethics. This study was conducted in accordance with the ethical guidelines of the World Medical Association Declaration of Helsinki-Ethical Principles for Medical Research Involving 
Human Subjects and has been approved by the Institutional Review Board of Nagoya University, Japan. All patients gave written informed consent for usage of clinical samples and data, as required by the institutional review board.

Sample collection and DNA preparation. Nine HCC cell lines (HepG2, Hep3B, HLE, HLF, HuH1, HuH2, HuH7, PLC/PRF-5 and SK-Hep1) were obtained from the American Type Culture Collection (Manassas, VA, USA). The cell lines were cultured in RPMI-1640 supplemented with $10 \%$ fetal bovine serum and incubated in $5 \% \mathrm{CO}_{2}$ at $37^{\circ} \mathrm{C}$.

A 68-year-old woman with chronic hepatitis $\mathrm{C}$ was diagnosed with $\mathrm{HCC}$ in the right lobe and underwent a liver resection. Specimens of her tumor and adjacent non-cancerous tissue were excised, and total RNA and DNA were extracted. Total RNA was sent to the manufacturer of Affymetrix to prepare it for expression array analysis. Genomic DNA was used in the SNP-Chip array, and bisulfite-converted DNA was used in the Illumina Infinium HumanMethylation27 BeadChip array (Illumina, San Diego, CA, USA). The tumor was pathologically confirmed as HCC. RNA and DNA were extracted from an area composed of $>80 \%$ cancerous cells in the tumor sample.

HCC tissue (HTs) and non-cancerous tissue (NTs) samples were obtained from 85 patients (72 males and 13 females) who underwent liver resection at Nagoya University Hospital, Nagoya, Japan between 1994 and 2001. Patient ages ranged from 21-77 years (mean \pm SD, 61.6 \pm 10.1 years). Sixty-one patients had hepatitis $\mathrm{C}$ and 16 had hepatitis $\mathrm{B}$. The median duration of follow-up was 63.4 months (range, 2.3-208.9 months). All tissues were reviewed pathologically to confirm the diagnosis of HCC. Written informed consent, as required by the institutional review board, was obtained from all patients. Tissue samples were immediately frozen in liquid nitrogen and stored at $-80^{\circ} \mathrm{C}$ until required. Genomic DNA was obtained from tissue samples using proteinase $\mathrm{K}$ digestion followed by phenol/ chloroform extraction.

RNA isolation and microarray procedure. Total RNA was isolated from each of the frozen samples with RNeasy Mini kit (Qiagen, Chatsworth, CA, USA) according to the manufacturer's protocol. RNA quality was assessed as an RNA integrity number $\geq 8$ using an Agilent 2100 Bioanalyzer (Missisauga, ON, Canada). Total RNA was labeled with cyanine-3 dye using a Quick Amp Labeling kit (Agilent) and hybridized to Agilent Whole Human Genome (4x44 K) Microarrays for $17 \mathrm{~h}$ in a rotating SciGene model 700 oven (Sunnyvale, CA, USA). Arrays were scanned using an Agilent Technologies DNA Microarray Scanner, and data were feature-extracted using Feature Extraction Software 10.5.1.1 (Agilent) and statistically analyzed using default setting on GeneSpring GX 12.1.0 software (Agilent) (26).

GeneChip Affymetrix platform. SNP chip array experiments were done according to the standard protocol for Affymetrix GeneChip Mapping $500 \mathrm{~K}$ arrays (Affimetrix). Briefly, total genomic DNA was digested with a restriction enzyme (XbaI or HindIII), ligated to an appropriate adapter for each enzyme, and subjected to PCR amplification using a single primer. After digestion with DNase I, the PCR products were labeled with a biotinylated nucleotide analogue using terminal deoxynucleotidyl transferase and hybridized to the microarray. Hybridized probes were captured by streptavidin-phycoerythrin conjugates, and the array was scanned and genotypes called as previously described (27).

All the examples of copy number analysis with Affymetrix GeneChip Mapping $500 \mathrm{~K}$ arrays were done using Copy Number Analyzer for Affymetrix GeneChip Mapping $500 \mathrm{~K}$ arrays (CNAG) version 2.0 (28).

Methylation array platform. Methylation arrays were performed using DNA extracted from tissue samples obtained from the 68-year-old female patient, as described above. The Illumina Infinium HumanMethylation27 BeadChip protocol required $0.5-1 \mu \mathrm{g}$ of bisulfite-converted DNA (29). Of the approximately 28 million $\mathrm{CpG}$ sites found throughout the haploid human genome, Illumina initially designed Infinium methylation probes for $27,578 \mathrm{CpG}$ sites located in promoter regions (up to $1 \mathrm{~kb}$ upstream or $500 \mathrm{bp}$ downstream of transcription start sites). Of these, $27,324 \mathrm{CpG}$ sites relate to 14,475 consensus coding sequences, including around 1,000 cancer-associated genes, and $254 \mathrm{CpG}$ sites relate to approximately 100 microRNA genes. The probes were preferentially selected to occur within $\mathrm{CpG}$ islands using the NCBI 'relaxed' definition of a $\mathrm{CpG}$ island: $\mathrm{CpG}$ islands identified bioinformatically with a $\mathrm{CpG}$ content of $>50 \%$ and an observed/expected ratio of $>0.6$ (30).

Bisulfite-converted DNA was then whole-genome amplified, enzymatically fragmented and hybridized to the array. During hybridization, the bisulfite-converted DNA annealed to methylation-specific probes on the chip. Each $\mathrm{CpG}$ locus was represented by two bead types, one of which was specific to the methylated state and the other specific to the unmethylated state, which was directly related to the underlying sequence change catalyzed during bisulfite conversion. Therefore, for each $\mathrm{CpG}$ site, a possible $\mathrm{C} / \mathrm{T}$ variant could be assayed through the single-base extension step, which was possible because of the ability to hybridize to either the 'protected' methylated cytosine or the converted (unmethylated) thymine.

After hybridization, a single-base extension step was carried out using a multi-layer staining process, as described below. The BeadChip was then scanned on the Illumina iScan and the resulting 'idat' files were analyzed using BeadStudio software. The output of the BeadStudio analysis was a $\beta$-value for each $\mathrm{CpG}$ site. This was a continuous value between 0 and 1 where $0=0 \%$ methylation and $1=100 \%$ methylation at a given $\mathrm{CpG}$ site. Therefore, this assay enables quantitative analysis of methylation at individual $\mathrm{CpG}$ sites.

The data were extensively analyzed and $C C N J$ was eventually identified as a potential cancer-related gene. Since the gene was identified from a specimen from a single patient, the result could have been applicable only to that particular patient. We therefore conducted additional experiments to verify the clinical relevance of $C C N J$.

Reverse transcription-polymerase chain reaction ( $R T-P C R)$. $C C N J$ mRNA expression was analyzed using semi-quantitative RT-PCR and real-time RT-PCR. Total RNA $(10 \mu \mathrm{g})$ isolated from nine HCC cell lines, primary HTs and NTs were used to generate cDNAs. The resulting cDNAs were then amplified 
Table I. Expression array analysis of the CCNJ gene.

\begin{tabular}{lcccccccc}
\hline $\begin{array}{l}\text { Probe set } \\
\text { ID }\end{array}$ & $\begin{array}{c}\text { Gene } \\
\text { symbol }\end{array}$ & $\begin{array}{c}\mathrm{Log}_{2} \\
\text { ratio }\end{array}$ & $\begin{array}{c}\text { Non-cancer } \\
\text { signal }\end{array}$ & Detection & $\begin{array}{c}\text { Tumor } \\
\text { signal }\end{array}$ & Detection & Probe ID & $\begin{array}{c}\text { Chromosomal } \\
\text { location }\end{array}$ \\
\hline 229091_s_at & CCNJ & -2.3 & 36.9 & $\mathrm{P}$ & 10.3 & $\mathrm{P}$ & HU133p2_38346 & $10 \mathrm{q} 24.1$ \\
219670_x_a & $C C N J$ & -1.3 & 31.6 & $\mathrm{P}$ & 11.2 & $\mathrm{P}$ & HU133p2_28755 & $10 \mathrm{q} 24.1$ \\
\hline
\end{tabular}

using PCR primers for $C C N J$ (sense, 5'-TGC GCT TTC CTG CCT GCT TC-3' in exon 3; antisense 5'-AGG CTG TTG AGC TGC TCC AG-3' in exon 4), which amplified an 81-bp product. Initial denaturation at $94^{\circ} \mathrm{C}$ for $5 \mathrm{~min}$ was followed by amplification consisting of 37 cycles of $94^{\circ} \mathrm{C}$ for $10 \mathrm{sec}$, $60^{\circ} \mathrm{C}$ for $8 \mathrm{sec}$ and $72^{\circ} \mathrm{C}$ for $6 \mathrm{sec}$. RT-PCR of $\beta$-actin was performed to confirm that equal amounts of cDNA were used as templates. Each PCR product was loaded directly onto $3 \%$ agarose gels, stained with ethidium bromide and visualized under UV illumination.

Quantitative RT-PCR analysis. PCR was performed with the SYBR Green PCR Core Reagents kit (Perkin-Elmer Applied Biosystems, Foster City, CA, USA) under the following conditions: one cycle at $95^{\circ} \mathrm{C}$ for $10 \mathrm{sec}$, followed by 40 cycles at $95^{\circ} \mathrm{C}$ for $5 \mathrm{sec}$ and at $60^{\circ} \mathrm{C}$ for $30 \mathrm{sec}$. SYBR Green emission was detected in real-time with an ABI prism 7000 Sequence Detector (Perkin-Elmer Applied Biosystems). Primers used in the PCR were the same as those described above for RT-PCR. For standardization, the expression of $G A P D H$ was quantified in each sample. Quantitative RT-PCR was performed at least three times, including negative controls without template. Expression of $C C N J$ was normalized to that of GAPDH in each sample.

Methylation-specific PCR (MSP). DNA from HCC cell lines, HTs and NTs were subjected to bisulfite treatment. Briefly, $2 \mu \mathrm{g}$ of DNA were denatured using $\mathrm{NaOH}$ and modified using sodium bisulfite. DNA samples were then purified using Wizard purification resin (Promega Corp., Madison, WI, USA), treated with $\mathrm{NaOH}$, precipitated with ethanol and resuspended in water. Primer pairs were used to detect methylation (sense, 5'-GGC GGT TGA GCG TTT CGG-3'; antisense, 5'-AAA CGA CGC GAC GAC TC-3'; 104-bp product) and nonmethylation (sense, 5'-GTT GTG TGG GAT GTT GAT TG-3'; antisense, 5'-CCA AAC CCA AAT ACA ACA GC-3'; 70-bp product) of the $C C N J$ promoter region near exon 1. MSP and unmethylated-specific PCR (UNMSP) amplification consisted of denaturation at $94^{\circ} \mathrm{C}$ for 5 min followed by 35 cycles of $94^{\circ} \mathrm{C}$ for $8 \mathrm{sec}, 60^{\circ} \mathrm{C}$ for $5 \mathrm{sec}$, and $72^{\circ} \mathrm{C}$ for $3 \mathrm{sec}$. PCR products were loaded directly onto $3 \%$ agarose gels, stained with ethidium bromide and visualized under UV illumination.

Sequence analysis. Bisulfite-treated genomic DNA obtained from HCC cell lines was sequenced and PCR was performed in all cases. Semi-nested PCR was performed to obtain adequate products for TA cloning. PCR amplification consisted of denaturation at $94^{\circ} \mathrm{C}$ for $3 \mathrm{~min}$ followed by 35 cycles of $94^{\circ} \mathrm{C}$ for $10 \mathrm{sec}, 52^{\circ} \mathrm{C}$ for $10 \mathrm{sec}$ and $72^{\circ} \mathrm{C}$ for $20 \mathrm{sec}$ with the following primer pair: sense 5'-GGA TTG GGT ATT GTTA GTG AT-3'; antisense, 5'-ACC TCA ACT AAA ACC CAA C-3'; yielding a 378-bp product. PCR products were subcloned into a TA cloning vector (Invitrogen, Carlsbad, CA, USA). Six cloned samples that originated from two HCC cell lines (SK-Hepl and Hep3B) were picked out. Each DNA clone was mixed with $3 \mu 1$ of the specific primer (M13) and $4 \mu 1$ of Cycle Sequence Mix (ABI PRISM Terminator v1.1 Cycle Sequencing kit; Applied Biosystems, Foster City, CA, USA). Samples were then subjected to the following cycling conditions: $95^{\circ} \mathrm{C}$ for $30 \mathrm{sec}$ followed by 25 cycles of $96^{\circ} \mathrm{C}$ for $10 \mathrm{sec}, 50^{\circ} \mathrm{C}$ for $5 \mathrm{sec}$, and $60^{\circ} \mathrm{C}$ for $4 \mathrm{~min}$, and then purified using ethanol precipitation. Sequence analysis was carried out using an Applied Biosystems ABI310, and sequence electropherograms were generated using ABI Sequence Analysis software version 3.0.

5-Aza-2'-deoxycytidine (5-aza-dC) treatment. To confirm that promoter hypermethylation was responsible for silencing of gene expression, the nine HCC cell lines were treated with $1 \mu \mathrm{M}$ 5-aza-dC (Sigma-Aldrich, St. Louis, MO, USA) to inhibit DNA methylation. Cells $\left(1.5 \times 10^{6}\right)$ were cultured for 6 days with medium changes on days 1, 3 and 5. On day 6 , cells were harvested, RNA was extracted, and RT-PCR was performed as described above.

Statistical analysis. Continuous variables were expressed as medians (range) and comparisons were made using the MannWhitney U test. Categorical variables were compared using $\chi^{2}$ or Fisher's exact tests, where appropriate. Overall survival rates were analyzed using Kaplan-Meier and log-rank tests. All statistical analyses were performed using JMP software version 9.0.2 (SAS International Inc., Cary, NC, USA). The level of statistical significance was set at $\mathrm{P}<0.05$.

\section{Results}

Expression, SNP and methylation arrays. To identify novel tumor-related genes in HCC, we used expression arrays and found genes whose expression was decreased in HCC samples compared with corresponding non-cancerous tissues. The result of the expression profiling showed that the expression of $C C N J$ was strongly decreased with a $-2.3\left(\log _{2}\right.$ ratio) value in the HCC expression array (Table I).

We then confirmed the reduction of expression of $C C N J$ in tumor tissues using semi-quantitative RT-PCR for case samples used in the array analysis (Fig. 1A). Next, we analyzed the SNP arrays. We observed deletions in 3q, 8p, 11q, 12p, 12q, $16 \mathrm{p}, 17 \mathrm{p}, 19 \mathrm{p}$ and $\mathrm{X}$ chromosomes, and chromosomal gains in 1q, 3q, 11q, 12p and 12q. Chromosome 10, which contains $C C N J$, did not show any deletions or amplifications (Fig. 1B). We also looked for detailed data of the SNP array at the CCNJ 

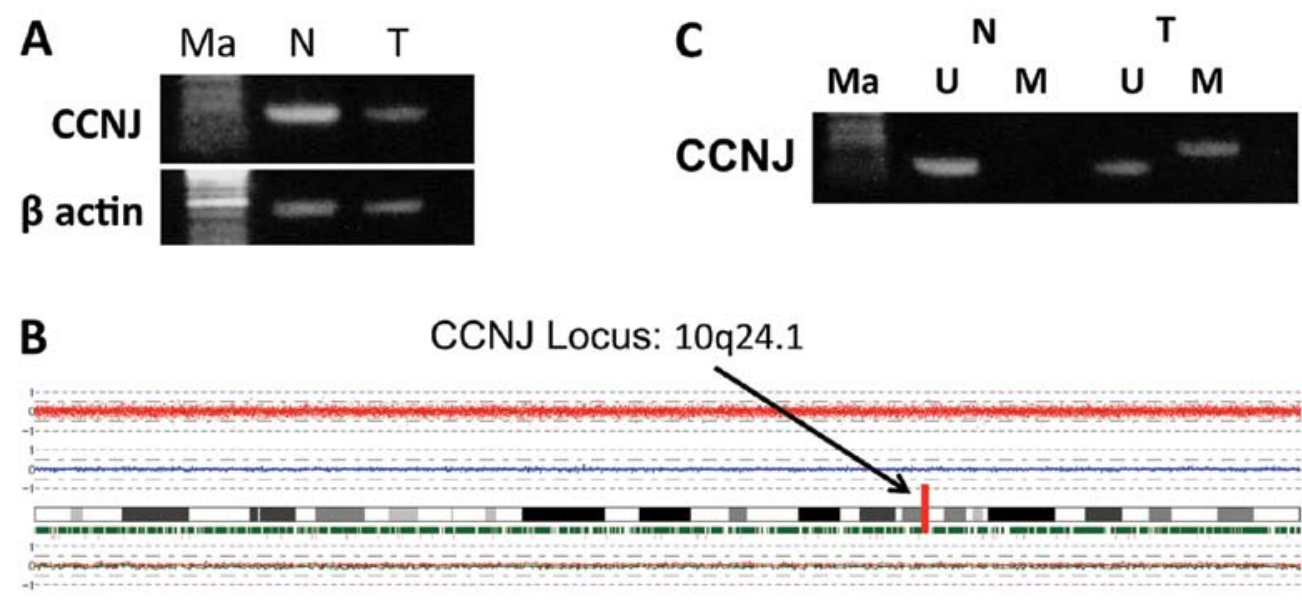

Figure 1. (A) RT-PCR results. RT-PCR was performed using RNA prepared from tissue samples from a 68-year-old woman and showed downregulation of $C C N J$ in the tumor sample compared with the corresponding adjacent non-cancerous tissue. (B) Copy number analysis of chromosome 10 using an SNP array on an HCC sample. There was no deletion or amplification on chromosome 10q24.1. (C) MSP and UMSP results. MSP showed promoter hypermethylation of DNA in tumor tissue from the 68-year-old woman. Ma, marker; N, normal tissue; T, tumor tissue; M, MSP; U, UNMSP.

Table II. Methylation array analysis of the HCC samples.

\begin{tabular}{lcccccc}
\hline Probe set ID & Chromosome & Physical position & Non-cancer & 1_Confidence & Tumor & 2_Confidence \\
\hline SNP_A_4268671 & 10 & 97804751 & AB & 0.003906 & AB & 0.002441 \\
SNP_A_2004209 & 10 & 97804806 & AA & 0.25 & AA & 0.039063 \\
SNP_A-4289679 & 10 & 97807640 & AB & 0.011719 & AB & 0.088379 \\
SNP_A-1922485 & 10 & 97808330 & AA & 0.0625 & AA & 0.007813 \\
\hline
\end{tabular}

Table III. Methylation array analysis of the CCNJ gene.

\begin{tabular}{|c|c|c|c|c|c|c|c|c|}
\hline \multirow{2}{*}{$\begin{array}{l}\text { Probe } \\
\text { ID }\end{array}$} & \multirow{2}{*}{$\begin{array}{l}\text { Gene } \\
\text { symbol }\end{array}$} & \multirow{2}{*}{ Sample } & \multirow{2}{*}{$\begin{array}{l}\text { Methylation } \\
\text { value }\end{array}$} & \multirow{2}{*}{ Total } & \multicolumn{2}{|c|}{ Status } & \multirow{2}{*}{ Confidence } & \multirow{2}{*}{$\begin{array}{c}\text { Chromosomal } \\
\text { location }\end{array}$} \\
\hline & & & & & Unmethylated & Methylated & & \\
\hline 229091_s_at & CCNJ & Normal & 0.112033 & 1346 & 1184 & 162 & $3.678 \mathrm{E}-38$ & $10 \mathrm{q} 24.1$ \\
\hline 219670_x_a & $C C N J$ & Tumor & 0.906054 & 3732 & 260 & 3472 & $3.678 \mathrm{E}-38$ & \\
\hline
\end{tabular}

gene locus at 10q24.1, and found four SNPs. Two of these four SNPs showed a heterozygous AB allele in both tumor and non-tumor tissue samples (Table II). These results suggested that the expression of $C C N J$ decreased without loss of heterozygosity $(\mathrm{LOH})$ or gene deletion.

We subsequently checked the results of the methylation array: the continuous $\beta$-values were 0.906 for tumor tissue vs. 0.112 for corresponding non-cancerous tissue, indicating a high degree of methylation in HCC samples (Table III). Using MSP, we confirmed the hypermethylation of the $C C N J$ promoter in the tumor tissue obtained from the 68-year-old woman whose DNA was used for the methylation array (Fig. 1C). These results implied that $C C N J$ expression decreased without $\mathrm{LOH}$, possibly because of hypermethylation of the promoter region.

MSP and UNMSP of nine HCC cell lines. We designed primers for methylation-specific MSP and UNMSP and checked the methylation status of nine HCC cell lines. For MSP, we obtained bands of appropriate size in lanes containing HLF, HepG2 and SKHep1 samples, while in UNMSP, appropriate bands were identified in lanes for all cell lines (Fig. 2A). We subsequently identified partial methylation in HLF, HepG2 and SKHep1, and no methylation in $\mathrm{HuH} 1, \mathrm{HuH} 2, \mathrm{HuH} 7$, Hep3B, HLE and PLC/PRF/5 cells.

5-Aza-dC treatment of nine HCC cell lines. To confirm that hypermethylation of the promoter in the lesion inhibited $C C N J$ expression, we checked mRNA expression of the gene before and after 5-aza-dC treatment in the nine HCC cell lines. After 5-Aza-dC treatment, expression of CCNJ in HLF, HepG2 and SKHepl cells was clearly reactivated, as shown using semiquantitative RT-PCR (Fig. 2B).

Sequence analysis. To confirm that the amplification of MSP was done correctly, we performed sequence analysis of bisulfite-treated DNA of the CCNJ promoter region cloned 

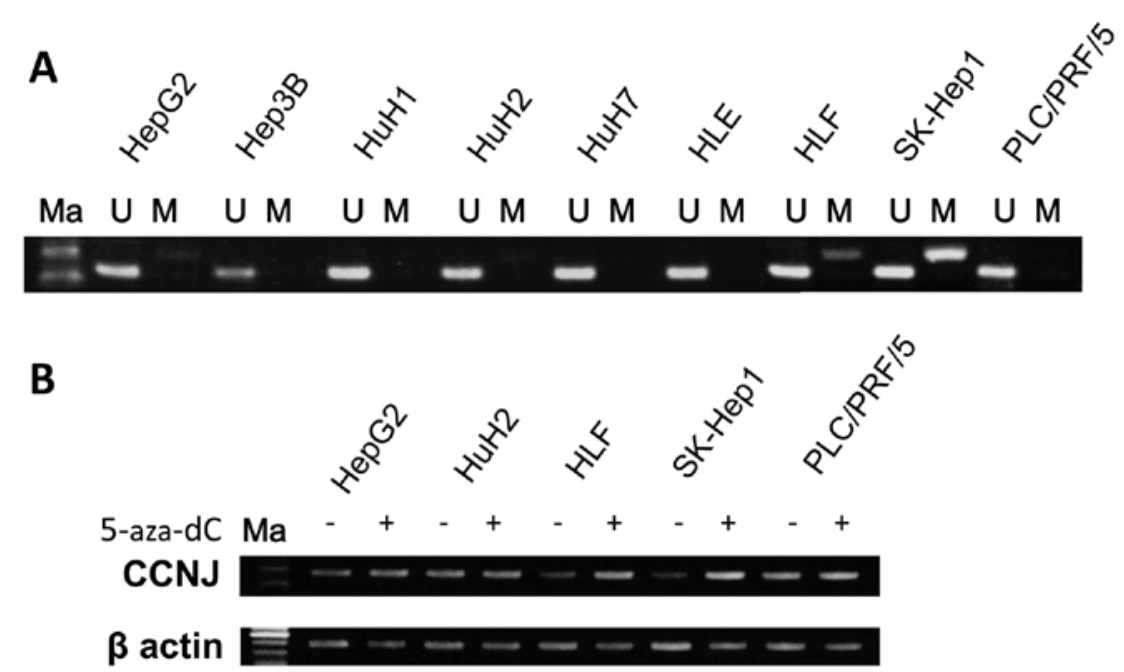

Figure 2. (A) Methylation status of the $C C N J$ gene in HCC cell lines; HepG2, HLF and SK-Hep1 showing hypermethylation. (B) Reactivation of $C C N J$ gene expression using 5-aza-dC treatment in HCC cell lines; HLF, HepG2 and SK-Hep1 were reactivated after 5-aza-dC treatment.

A

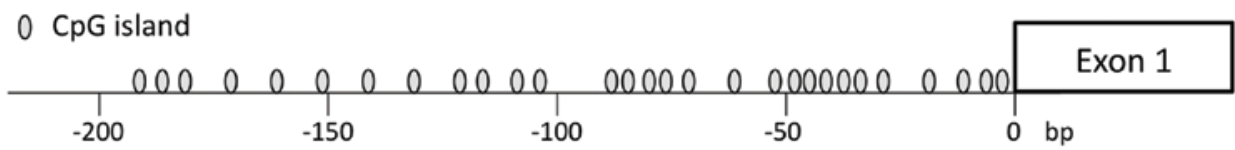

B

SK-Hep1

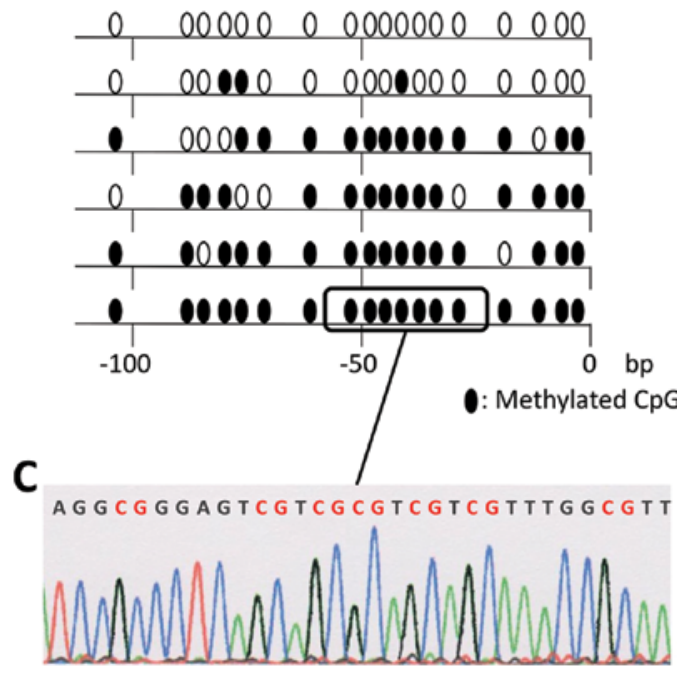

Hер3в

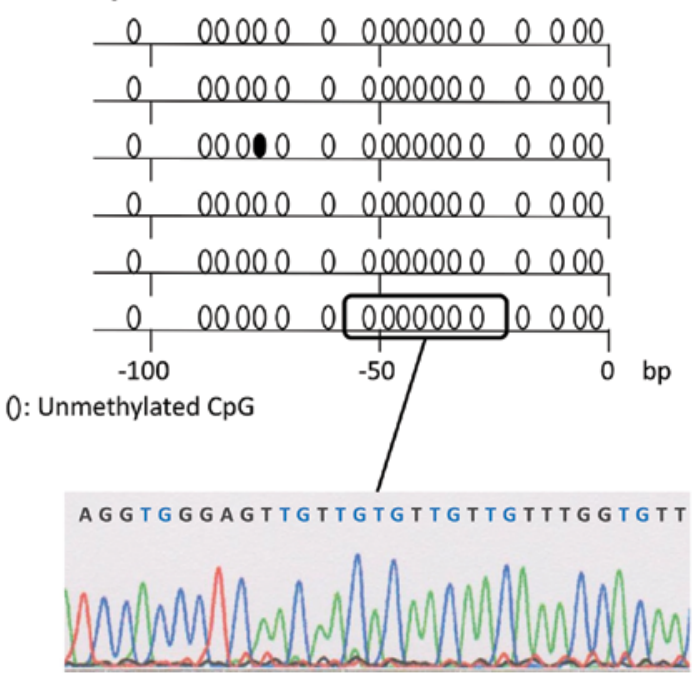

Figure 3. (A) The CpG island in the $C C N J$ promoter region. (B) Some of the six clones of the $C C N J$ promoter region; five of six of the CpG islands in the promoter region in almost all SK-Hep1 cells were methylated, whereas no methylation was detected in Hep3B cells. (C) Sequential analysis of bisulfite-treated DNA from SK-Hep1 and Hep3B cells was localized in the CCNJ promoter region; C bases indicates methylated CpG island in SK-Hep1 cells. T bases were converted from $\mathrm{C}$ using bisulfite treatment, and revealed unmethylated $\mathrm{CpG}$ islands in Hep3B cells.

into TA cloning vectors with cDNAs from both SK-Hep1 and Hep3B cells. Almost all CpG islands in cDNA fragments isolated from SKHep1 cells were methylated, while those from Hep3B were unmethylated (Fig. 3). These results showed the high degree of accuracy of MSP and UNMSP.

MSP and UNMSP of adjacent non-cancerous and tumor tissues from $85 \mathrm{HCC}$ patients. We assessed CCNJ promoter hypermethylation in adjacent non-cancerous and tumor tissues from 85 HCC patients. Overall, 67 of the 85 (78.8\%) displayed CCNJ promoter hypermethylation in HCC tissues, compared with eight of $85(9.4 \%)$ in adjacent non-cancerous tissues (Fig. 4A). Hypermethylation of the $C C N J$ promoter occurred statistically significantly more frequently in tumor tissues $(\mathrm{P}<0.001)$.

Quantitative RT-PCR analysis of specimens from $85 \mathrm{HCC}$ patients. We evaluated expression levels of CCNJ mRNA using real-time RT-PCR in the 85 cases, and by calculating the expression index (the value of $C C N J$ mRNA expression divided by that of $G A P D H$ for each sample). Total $C C N J$ expression in tumor tissues was significantly lower compared 
A

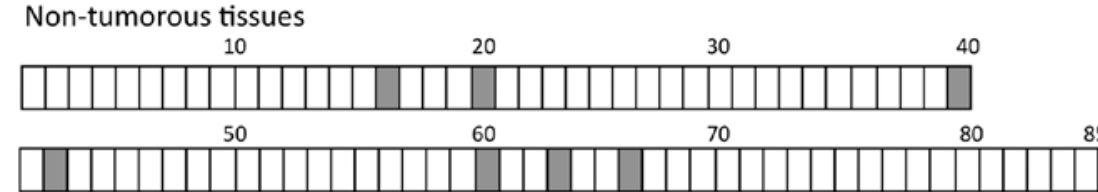

Tumor tissues

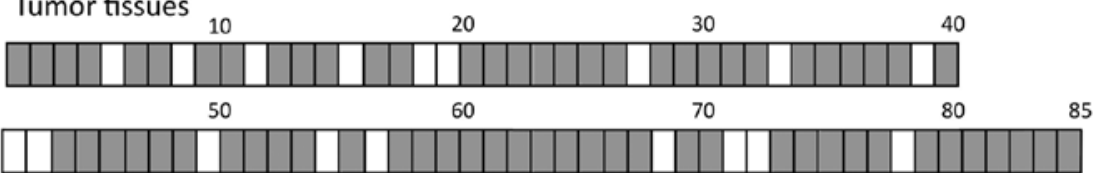

Methylation $\square$ Un-methylation

B

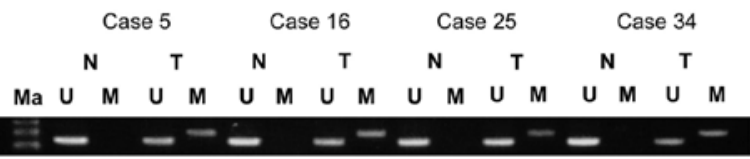

C

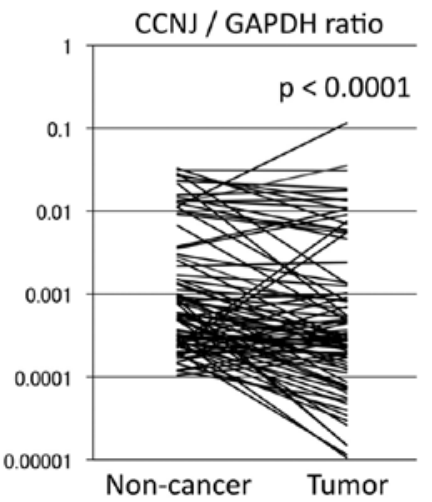

Figure 4. (A) Methylation status of the CCNJ promoter region in non-tumor/tumor tissues of $85 \mathrm{HCC}$ patients. (B) Four samples of paired normal and tumor tissue were chosen at random and analyzed for $C C N J$ methylation. (C) Total CCNJ expression in tumor tissue was significantly lower than that in non-tumor tissue. Ma, marker; M, MSP; U, UMSP; N, non-cancer tissue; T, tumor tissue.

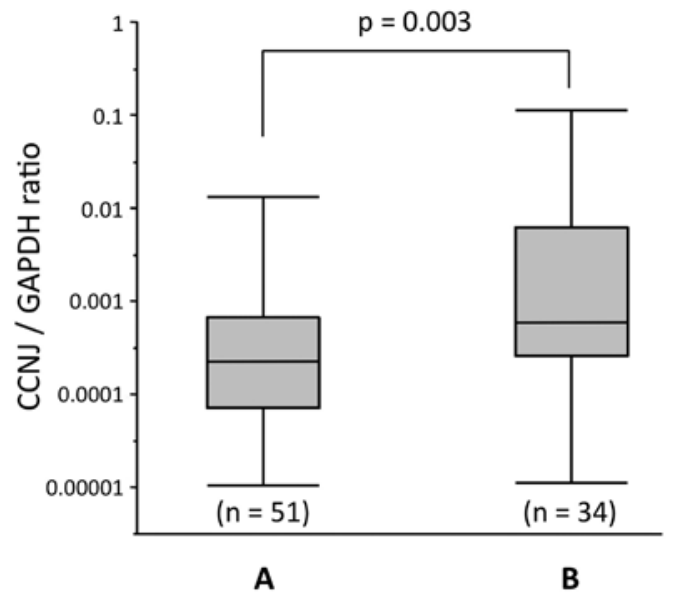

Figure 5. Correlation between methylation status and expression of $C C N J$ in tumor tissues of $85 \mathrm{HCC}$ patients. Cases that showed both promoter hypermethylation and downregulation of $C C N J$ had significantly lower expression of $C C N J$ than cases without promoter hypermethylation. (A) Cases with methylation and downregulation of $C C N J$. (B) Other cases.

with that in adjacent non-cancerous tissues $(\mathrm{P}<0.001$; Fig. 4C). Furthermore, the cases with $C C N J$ promoter hypermethylation showed significantly lower expression of $C C N J$ in tumor tissues than those without promoter hypermethylation (Fig. 5).

Association between promoter methylation status of the CCNJ gene and clinicopathological characteristics in 85 HCC patients. We analyzed the association between the methylation status of $C C N J$ and clinicopathological features in the 85 HCC patients. There was no notable association between methylation status and clinicopathological factors (data not shown). However, cases with both hypermethylation and a lower expression value of $C C N J$ in tumor tissue than in adjacent non-cancerous tissue had a poorer prognosis in terms of overall survival than the other cases $(\mathrm{P}=0.038$; Fig. 6).

\section{Discussion}

The cell cycle is controlled by a highly conserved family of proteins called cyclin-dependent kinases (CDKs) and their regulatory subunits, the cyclins (31). In mammals, approximately 20 subtypes of cyclin family members have been detected. The progression of the cell cycle requires the cyclic activity of several distinct CDK/cyclin complexes. The transition from the $\mathrm{G} 2$ to the mitotic (M) phase requires active complexes consisting of CDK1/cyclin, and from the G1 to the synthesis (S) phase requires active CDK2/cyclin complexes (32).

$C C N J$ was previously identified in a yeast two-hybrid screen for embryonic proteins that interact with CDK2 (33). The biological function of $C C N J$ in humans is still unclear, but in Drosophila early embryogenesis, a role for $C C N J$ in nuclear division has been reported. In the early embryo of Drosophila, CCNJ is present in the $\mathrm{S}$ phase in an active complex with CDK2. Thus, CDK2/CCNJ complexes may be functioning during the $\mathrm{S}$ phase in the cell cycle (34).

In humans, the function of several cyclin family members has been linked to the process of carcinogenesis 


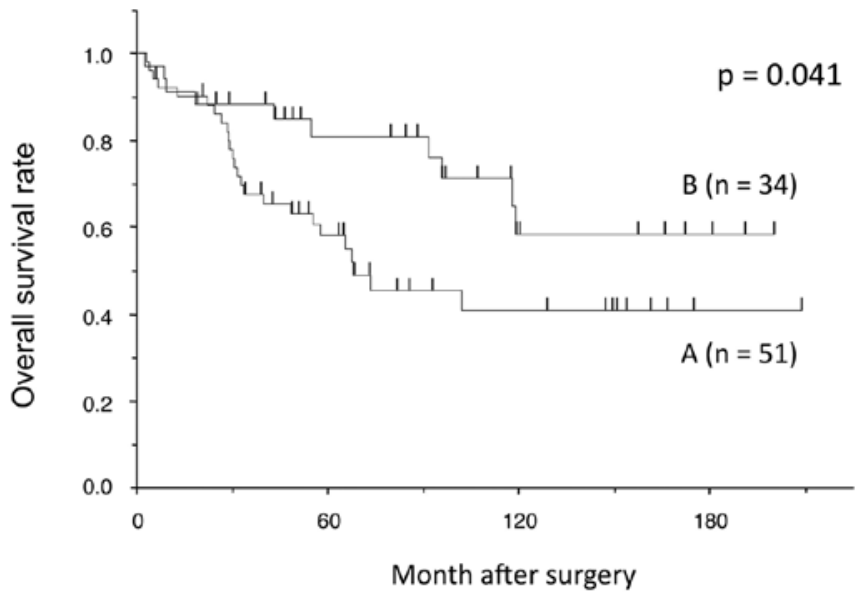

Figure 6. Overall survival rate of cases with methylation and lower expression of $C C N J$ compared with the other cases; a case with both hypermethylation and lower expression of $C C N J$ in the tumor tissue had a significantly poorer prognosis $(\mathrm{P}=0.038)$. (A) The cases with methylation and lower expression of CCNJ. (B) The other cases.

or proliferation of cancer, and many of them are considered to be oncogenic. Also, in human HCC, the correlation between tumor progression and overexpression of some cyclin family members has been reported. Nishida et al reported that overexpression of CCNDI resulted in the rapid growth of HCC (35). Gramantieri et al reported that CCNG1 was inversely correlated with miR-122, which influences p53 stability and transcriptional activity, and higher $C C N G 1$ expression was related to decreased survival $(36,37)$. However, our results showed that downregulation with promoter hypermethylation of $C C N J$ in tumor tissues correlated with a significantly poorer prognosis.

Similar to our results, cyclin $\mathrm{G} 2(C C N G 2)$ has been reported to be a tumor suppressor gene, and it has been shown that the level of $C C N G 2$ was downregulated in human gastric adenocarcinomas (18), oral squamous carcinomas (19), colorectal carcinomas (20) and bladder metastatic carcinomas (21), when compared with adjacent non-cancerous tissues. Moreover, low levels of $C C N G 2$ expression correlated significantly with poor overall survival (22).

The biological function of $C C N G 2$ is obviously different from conventional cell cycle proteins, since $C C N G 2$ negatively regulates cell cycle progression (23). DNA damage and other growth inhibitory signals may upregulate the activity of the $C C N G 2$ gene, and activated $C C N G 2$ interacts with protein phosphatase $2 \mathrm{~A}$ (PP2A) and the $C C N G 2-\mathrm{PP} 2 \mathrm{~A}$ complex stops cell cycle progression and regulates cell proliferation by inhibiting CDK2 (38). As indicated by our results, CCNJ behaved similarly to $C C N G 2$ in that it had a suppressive role against tumor progression by regulating the $\mathrm{G} 1$ to $\mathrm{S}$ phase transition of the cell cycle, because $C C N J$ is considered to interact with CDK2 in the cell cycle.

In conclusion, our results indicated that $C C N J$ could be a novel prognostic marker of HCC. The mechanism of $C C N J$ silencing might be related to promoter hypermethylation. The method of triple combination array analysis, which we devised, may be potentially useful in detecting new tumor-related genes and their mechanisms.

\section{Acknowledgements}

This work was supported by Japan Society for the Promotion of Science (JSPS) KAKENHI Grant-in-Aid for Scientific Research (C) number 22591427.

\section{References}

1. Ferlay J, Shin HR, Bray F, Forman D, Mathers C and Parkin DM: Estimates of worldwide burden of cancer in 2008: GLOBOCAN 2008. Int J Cancer 127: 2893-2917, 2010.

2. Forner A, Llovet JM and Bruix J: Hepatocellular carcinoma. Lancet 379: 1245-1255, 2012.

3. Livraghi T, Goldberg SN, Lazzaroni S, Meloni F, Solbiati L and Gazelle GS: Small hepatocellular carcinoma: Treatment with radio-frequency ablation versus ethanol injection. Radiology 210: 655-661, 1999.

4. Takayasu K, Arii S, Ikai I, et al: Liver Cancer Study Group of Japan: Prospective cohort study of transarterial chemoembolization for unresectable hepatocellular carcinoma in 8510 patients. Gastroenterology 131: 461-469, 2006.

5. Llovet JM, Ricci S, Mazzaferro V, et al: SHARP Investigators Study Group: Sorafenib in advanced hepatocellular carcinoma. N Engl J Med 359: 378-390, 2008.

6. Yu MC and Yuan JM: Environmental factors and risk for hepatocellular carcinoma. Gastroenterology 127 (Suppl 1): S72-S78, 2004.

7. Cusnir M and Patt YZ: Novel systemic therapy options for hepatocellular carcinoma. Cancer J 10: 97-103, 2004.

8. El-Serag HB and Rudolph KL: Hepatocellular carcinoma: Epidemiology and molecular carcinogenesis. Gastroenterology 132: 2557-2576, 2007.

9. Kanda M, Nomoto S, Okamura Y, Nishikawa Y, Sugimoto H, Kanazumi N, Takeda S and Nakao A: Detection of metallothionein $1 \mathrm{G}$ as a methylated tumor suppressor gene in human hepatocellular carcinoma using a novel method of double combination array analysis. Int J Oncol 35: 477-483, 2009.

10. Nomoto S, Kanda M, Okamura Y, Nishikawa Y, Qiyong L, Fujii T, Sugimoto H, Takeda S and Nakao A: Epidermal growth factor-containing fibulin-like extracellular matrix protein 1 , EFEMP1, a novel tumor-suppressor gene detected in hepatocellular carcinoma using double combination array analysis. Ann Surg Oncol 17: 923-932, 2010.

11. Okamura Y, Nomoto S, Kanda M,Li Q, Nishikawa Y,Sugimoto H, Kanazumi N, Takeda S and Nakao A: Leukemia inhibitory factor receptor (LIFR) is detected as a novel suppressor gene of hepatocellular carcinoma using double-combination array. Cancer Lett 289: 170-177, 2010.

12. Okamura Y, Nomoto S, Kanda M, Hayashi M, Nishikawa Y, Fujii T, Sugimoto H, Takeda $S$ and Nakao A: Reduced expression of reelin (RELN) gene is associated with high recurrence rate of hepatocellular carcinoma. Ann Surg Oncol 18: 572-579, 2011.

13. Kanda M, Nomoto S, Okamura Y, Hayashi M, Hishida M, Fujii T, Nishikawa Y, Sugimoto H, Takeda S and Nakao A: Promoter hypermethylation of fibulin 1 gene is associated with tumor progression in hepatocellular carcinoma. Mol Carcinog 50: 571-579, 2011.

14. Hayashi M, Nomoto S, Kanda M, Okamura Y, Nishikawa Y, Yamada S, Fujii T, Sugimoto H, Takeda S and Kodera Y: Identification of the A kinase anchor protein 12 (AKAP12) gene as a candidate tumor suppressor of hepatocellular carcinoma. J Surg Oncol 105: 381-386, 2012.

15. Okamura Y, Nomoto S, Hayashi M, et al: Identification of the bleomycin hydrolase gene as a methylated tumor suppressor gene in hepatocellular carcinoma using a novel triple-combination array method. Cancer Lett 312: 150-157, 2011.

16. Hishida M, Nomoto S, Inokawa Y, et al: Estrogen receptor 1 gene as a tumor suppressor gene in hepatocellular carcinoma detected by triple-combination array analysis. Int J Oncol 43: 88-94, 2013.

17. Inokawa Y, Nomoto S, Hishida M, et al: Dynamin 3: A new candidate tumor suppressor gene in hepatocellular carcinoma detected by triple combination array analysis. Onco Targets Ther 6: 1417-1424, 2013.

18. Shi W, Yu KR, Wu GY and Zhang XB: Expression of CCNG in gastric carcinoma and its relationship with prognosis. Chin J Cell Biol 33: 994-997, 2011. 
19. Kim Y, Shintani S, Kohno Y, Zhang R and Wong DT: Cyclin G2 dysregulation in human oral cancer. Cancer Res 64: 8980-8986, 2004.

20. Sun GG, Zhang $\mathrm{J}$ and $\mathrm{Hu} \mathrm{WN}$ : CCNG2 expression is downregulated in colorectal carcinoma and its clinical significance. Tumour Biol 35: 3339-3346, 2014.

21. Shan G, Shan SG and Zhang XB: Expression of Cyclin G1 and Cyclin G2 in transitional cell carcinoma of bladder. Chin J Histochem Cytochem 18: 267-272, 2009.

22. Sun GG, Hu WN, Cui DW and Zhang J: Decreased expression of CCNG2 is significantly linked to the malignant transformation of gastric carcinoma. Tumour Biol 35: 2631-2639, 2014.

23. Bates S, Rowan S and Vousden KH: Characterisation of human cyclin G1 and G2: DNA damage inducible genes. Oncogene 13: 1103-1109, 1996.

24. Harvey RC, Mullighan CG, Wang X, et al: Identification of novel cluster groups in pediatric high-risk B-precursor acute lymphoblastic leukemia with gene expression profiling: Correlation with genome-wide DNA copy number alterations, clinical characteristics, and outcome. Blood 116: 4874-4884, 2010.

25. Feliciano A, Castellvi J, Artero-Castro A, et al: miR-125b act as a tumor suppressor in breast tumorigenesis via its novel direct targets ENPEP, CK2- $\alpha$, CCNJ, and MEGF9. PLoS One 8: e76247, 2013.

26. Stangegaard M: Gene expression analysis using agilent DNA microarrays. Methods Mol Biol 529: 133-145, 2009.

27. Kennedy GC, Matsuzaki H, Dong S, et al: Large-scale genotyping of complex DNA. Nat Biotechnol 21: 1233-1237, 2003.

28. Nannya Y, Sanada M, Nakazaki K, et al: A robust algorithm for copy number detection using high-density oligonucleotide single nucleotide polymorphism genotyping arrays. Cancer Res 65 : 6071-6079, 2005.
29. Takai D and Jones PA: The CpG island searcher: A new WWW resource. In Silico Biol 3: 235-240, 2003.

30. Jones PA and Baylin SB: The fundamental role of epigenetic events in cancer. Nat Rev Genet 3: 415-428, 2002.

31. Morgan DO: Cyclin-dependent kinases: Engines, clocks, and microprocessors. Annu Rev Cell Dev Biol 13: 261-291, 1997.

32. Satyanarayana A and Kaldis P: Mammalian cell-cycle regulation: Several Cdks, numerous cyclins and diverse compensatory mechanisms. Oncogene 28: 2925-2939, 2009.

33. Finley RL Jr, Thomas BJ, Zipursky SL and Brent R: Isolation of Drosophila cyclin D, a protein expressed in the morphogenetic furrow before entry into $S$ phase. Proc Natl Acad Sci USA 93: 3011-3015, 1996.

34. Kolonin MG and Finley RL Jr: A role for cyclin $\mathrm{J}$ in the rapid nuclear division cycles of early Drosophila embryogenesis. Dev Biol 227: 661-672, 2000.

35. Nishida N, Fukuda Y, Komeda T, et al: Amplification and overexpression of the cyclin D1 gene in aggressive human hepatocellular carcinoma. Cancer Res 54: 3107-3110, 1994.

36. Gramantieri L, Ferracin M, Fornari F, et al: Cyclin G1 is a target of miR-122a, a microRNA frequently down-regulated in human hepatocellular carcinoma. Cancer Res 67: 6092-6099, 2007.

37. Fornari F, Gramantieri L, Giovannini C, et al: MiR-122/cyclin G1 interaction modulates p53 activity and affects doxorubicin sensitivity of human hepatocarcinoma cells. Cancer Res 69: 5761-5767, 2009.

38. Bennin DA, Don AS, Brake T, McKenzie JL, Rosenbaum H, Ortiz L, DePaoli-Roach AA and Horne MC: Cyclin G2 associates with protein phosphatase $2 \mathrm{~A}$ catalytic and regulatory $\mathrm{B}$ ' subunits in active complexes and induces nuclear aberrations and a $\mathrm{G} 1 / \mathrm{S}$ phase cell cycle arrest. J Biol Chem 277: 27449-27467, 2002. 